\title{
Investigations on the Hot Stamping of AW-7921-T4 Alloy Sheet
}

\author{
M. Kumar ${ }^{1}$ and N. G. Ross ${ }^{2}$ \\ ${ }^{1}$ LKR Leichtmetallkompetenzzentrum Ranshofen GmbH, Austrian Institute of Technology, Lamprechtshausnerstrasse 61, Postfach 26, \\ 5282 Ranshofen, Austria \\ ${ }^{2}$ Robinson Research Institute, Victoria University of Wellington, 69 Gracefield Road, P.O. Box 33-436, Petone, \\ Lower Hutt 5046, New Zealand
}

Correspondence should be addressed to M. Kumar; mkm.iitr@gmail.com

Received 23 August 2016; Revised 24 November 2016; Accepted 26 January 2017; Published 26 February 2017

Academic Editor: Gianfranco Palumbo

Copyright ( 2017 M. Kumar and N. G. Ross. This is an open access article distributed under the Creative Commons Attribution License, which permits unrestricted use, distribution, and reproduction in any medium, provided the original work is properly cited.

\begin{abstract}
AW-7xxx alloys have been nowadays considered for greater light weighting potential in automotive industry due to its higher strength compared to AW-5xxx and AW-6xxx alloys. However, due to their lower formability the forming processes are still in development. This paper investigates one such forming process called hot stamping. The investigation started by carrying out hot tensile testing of an AW-7xxx alloy, that is, AW-7921 at temperatures between $350^{\circ} \mathrm{C}$ and $475^{\circ} \mathrm{C}$, to measure the strength and formability. Formability was found to improve with increasing temperature and was sensitive to the strain rate. Dynamic recovery is considered as usual reason for the formability improvement. However, examining the precipitation states of the as-received condition and after hot stamping using differential scanning calorimetry (DSC), the dissolution of precipitates was also believed to contribute to this increase in formability. Following solution heat treatment there was no precipitation during cooling across the cooling rates investigated $\left(5-10^{\circ} \mathrm{C} / \mathrm{s}\right)$. Samples taken from parts hot stamped at 10 and $20 \mathrm{~mm} \mathrm{~s}^{-1}$ had similar yield strengths. A 3 -step paint baking heat treatment yielded a higher postpaint baking strength than a single step treatment.
\end{abstract}

\section{Introduction}

B-pillars and other key automotive parts demand a high strength-to-weight ratio to satisfy the roof crush and side impact standards while keeping the weight down. High strength AW-7xxx alloys are ideal for satisfying this criterion and consequently are the focus of many investigations [1-3]. Due to poor formability at room temperature AW-7xxx alloys are mostly used in the aircraft industry/production and up to this time have only found limited use for automotive parts.

The limited cold formability of AW-7xxx sheet can be enhanced by either forming the material in the $\mathrm{W}$ - and $\mathrm{O}$ tempers or forming at warm temperatures [4-8]. Forming with $\mathrm{W}$ - and O-temper requires costly heat treatment steps to produce distortion-free parts. Additionally, the gain in formability from warm forming is modest compared to the substantial additional complexity of heating the tooling and blank. In contrast, a hot stamping process does not require alloys with particular tempers and can form parts at least as fast as cold forming. In this forming process, the aluminium achieves significantly higher ductility than in the warm forming process. This extends the application of hot stamping to the forming of parts with complex geometries.

Investigation into the hot stamping technology for forming aluminium sheet has only been carried out by a few researchers [9-11]. In a series of tensile tests between $350^{\circ} \mathrm{C}$ and $493^{\circ} \mathrm{C}$ the ductility of AA2024 sheet was shown by Wang et al. [9] to increase with temperature up to $450^{\circ} \mathrm{C}$, with further increase in temperature causing a sharp decrease in ductility. For the AA6082 alloy Mohamed et al. [10] found the largest drawing depth and most uniform part thickness when hot stamping the alloy would be achieved with a forming rate of approximately $0.21 \mathrm{~m} \mathrm{~s}^{-1}$. Using tensile and Nakazima tests at elevated temperatures Bariani et al. [11] found the optimum hot stamping formability of AA5083 sheet is at $450^{\circ} \mathrm{C}$ and successfully produced an underengine cover part in an industrial hot stamping plant.

In the hot stamping process of aluminium alloys the sheet is heated up to near the solution heat treatment temperature in the furnace. To reduce heat loss once heated it is transferred 


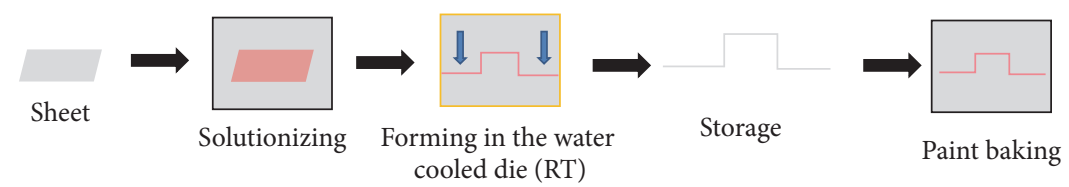

FIGURE 1: A simple schematic presentation of process steps in the hot stamping process chain.

TABLE 1: Chemical composition (in wt.\%).

\begin{tabular}{lcccccccccc}
\hline $\mathrm{Al}$ & $\mathrm{Si}$ & $\mathrm{Fe}$ & $\mathrm{Cu}$ & $\mathrm{Mn}$ & $\mathrm{Mg}$ & $\mathrm{Zn}$ & $\mathrm{Ni}$ & $\mathrm{Cr}$ & $\mathrm{Ti}$ & $\mathrm{Zr}$ \\
\hline Rest & 0.11 & 0.24 & 0.13 & 0.06 & 2.63 & 7.28 & 0.01 & 0.02 & 0.05 & 0.11 \\
\hline
\end{tabular}

as quickly as possible to the water cooled forming-dies. Quick forming of the sheet between the dies minimizes the heat loss and ensures a better quenching rate of the heated sheet between the forming-dies. For age-hardenable aluminium alloys the quenching rate should be fast enough to suppress any precipitation reactions. These conditions are essential to form good quality parts.

The hot stamping process chain consists of the following major steps: solution heat treatment of the sheet and quick transfer into the press, forming and die quenching, storage, and finally paint baking as shown in Figure 1. Considering this process chain, the usage of new AW-7xxx sheet as a structural material depends (in addition to the formability) on the age hardening response of the alloy during the forming process chain. In particular, it is important to achieve adequate strength during the paint baking step in order to produce a good quality product.

The main objective of the current work is to investigate the hot stamping of AW-7921-T4 sheet. Consideration is made of the processing parameters related to the transfer and quenching of the sheet, and how these influence the evolution of the microstructure and the mechanical properties in the stamped part. This is done by studying the quench sensitivity, forming, precipitation, and age hardening behaviour of the AW-7921-T4 sheet with the help of dilatometry (DIL), deep drawing, differential scanning calorimetry (DSC), and tension and hardness tests.

\section{Experimental}

2.1. Materials. An AW-7921 sheet in T4 condition with a thickness of $2 \mathrm{~mm}$ has been used in this work (Table 1).

2.2. Tension Test. Tensile samples were machined from the $2 \mathrm{~mm}$ thick AW-7921-T4 sheet in the direction of rolling. The tests were performed using an 805 A/D Bähr deformation dilatometer. Details of the tensile sample geometry and deformation dilatometer were given in [6]. Each tensile sample was heated to the test temperature in $6 \mathrm{~s}$ and soaked for $4 \mathrm{~s}$ before each tensile test as shown in Figure 2(a).

Tension tests were performed at temperatures ranging from $350^{\circ} \mathrm{C}$ to $475^{\circ} \mathrm{C}$ and at strain rates between 0.01 and $1 \mathrm{~s}^{-1}$. Additional tests were also performed at RT, 170 , and $230^{\circ} \mathrm{C}$ at $1 \mathrm{~s}^{-1}$. Tests were repeated at least three times to ensure reproducibility. Important parameters from the flow curve measured during the tension test were determined and are defined as follows:

Yield stress: stress at $0.2 \%$ offset true strain.

Peak stress: true stress at maximum load.

Elongation at fracture: engineering fracture strain, read from the engineering stress-strain flow curve.

Strain rate sensitivity, $m:[\partial \ln \sigma / \partial \ln \dot{\varepsilon}]_{\varepsilon}$, where $\sigma$ is the peak stress.

2.3. Dilatometry (DIL). DIL samples $(2 \mathrm{~mm} \times 4 \mathrm{~mm} \times$ $10 \mathrm{~mm}$ ) were solution-treated in the dilatometer at $480^{\circ} \mathrm{C}$ for $30 \mathrm{~min}$ and then continuously cooled to room temperature at various cooling rates between 1 and $3000 \mathrm{~K} \mathrm{~min}^{-1}$ using He gas. During continuous cooling the change in length of the samples was recorded by the dilatometer. Finally, the dilatometry (DIL) curves were numerically differentiated and plotted as $d \Delta L / d T$ versus $T$.

2.4. Deep Drawing a "Smiley" Shaped Part. The deep drawing of a "smiley" shape part is a simulative test used to evaluate hot stamping characteristics. In the current work deep drawing tests were carried out on rectangular $300 \mathrm{~mm} \times 400 \mathrm{~mm}$ AW-7921-T4 blanks in a 1.6 MN hydraulic press (Figure 2(b)). Multidraw Drylube C1 lubricant was applied to the tool. Each blank was heated in a furnace to a temperature near the solution heat treatment temperature $\left(470^{\circ} \mathrm{C}\right)$ before being transferred to the tool. During transfer, the blank lost some heat $\left(\sim 20^{\circ} \mathrm{C}\right)$, as measured by the thermocouple during the trials. After inserting the blank into the tool the die was closed, the blank holding pressure is applied, and the punch rose up to a height of $50 \mathrm{~mm}$ into the die. The total time for the deep drawing process took approximately $35 \mathrm{~s}$ as shown in Figure 2(c). Test parameters for deep drawing are listed in Table 2.

2.5. Tension Test of Sample from the Side-Wall Section of DeepDrawn "Smiley" Prototypes. Tensile samples of gauge length $25 \mathrm{~mm}$ and width $8 \mathrm{~mm}$ were machined according to the European Standard EN ISO 6892-1Bn from the wall-section of the deep-drawn smiley form, as shown in Figure 2(d), to evaluate the postforming strength. Some tensile samples were also further heat treated to simulate the conventional automotive paint baking heat treatments. One-step paint 


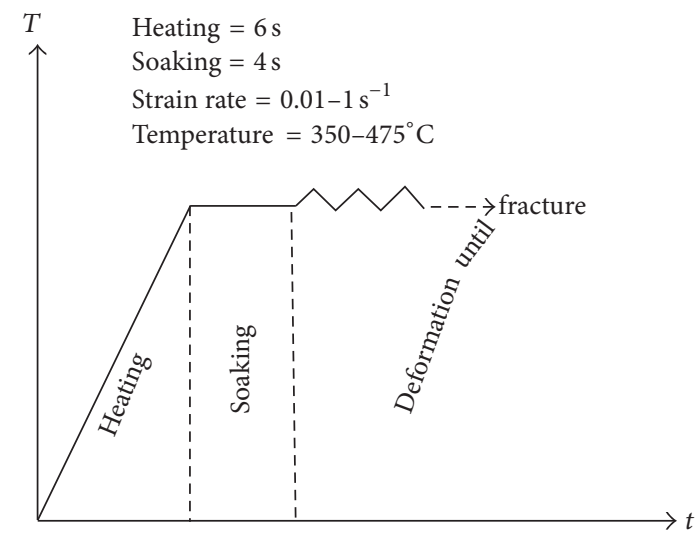

(a)

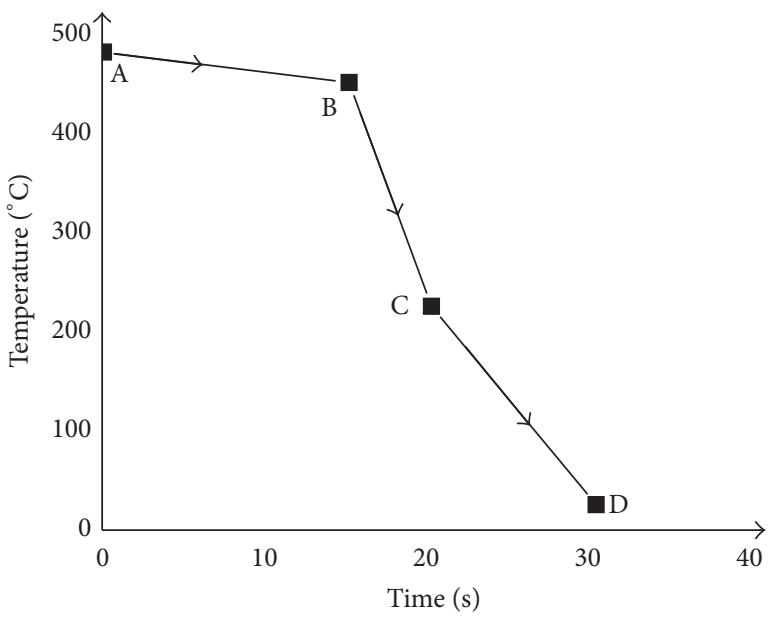

A to B: transfer to the press + die closing $\mathrm{B}$ to $\mathrm{C}$ : simultaneous forming + die quenching $\mathrm{C}$ to $\mathrm{D}$ : die opening + water quenching

(c)

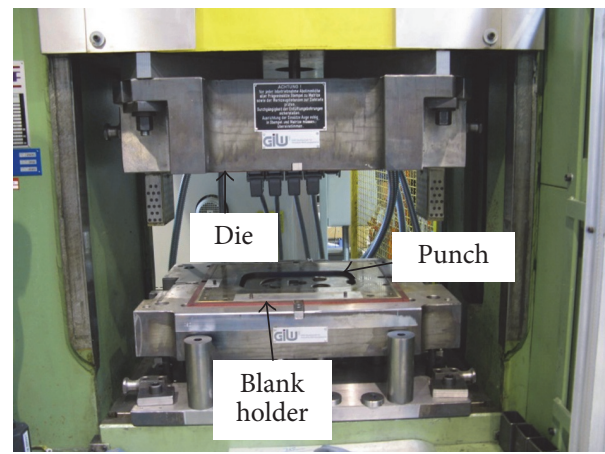

(b)

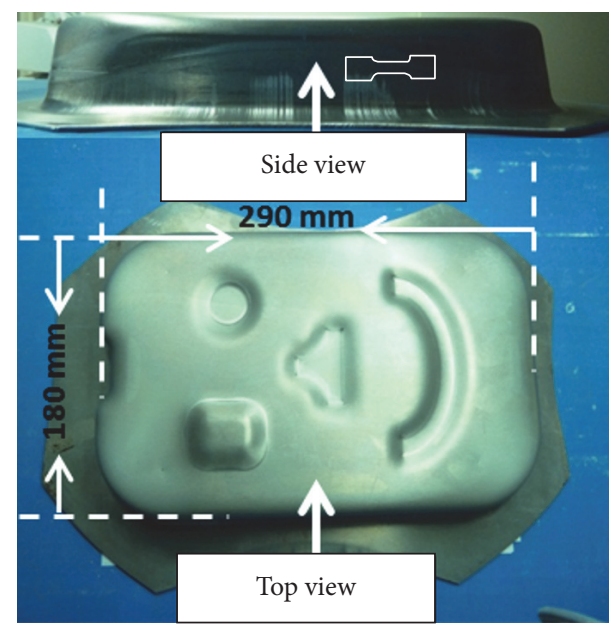

(d)

Figure 2: (a) Schematic of the tension tests procedure. (b) Hydraulic press with smiley form die, (c) schematic diagram showing a typical thermomechanical history for the deep drawing process, and (d) the smiley form prototype after deep drawing. The location from where samples were taken is also shown in (d).

TABLE 2: Test parameters for smiley shape deep drawing.

\begin{tabular}{lc}
\hline Parameter & Value \\
\hline Sheet thickness & $2 \mathrm{~mm}$ \\
Lubricant & Multidraw Drylube C1 \\
Deep drawing depth & $50 \mathrm{~mm}$ \\
Blank holding force & $75 \mathrm{kN}$ \\
Punch speed & 10 and $20 \mathrm{~mm} \mathrm{~s}^{-1}$ \\
\hline
\end{tabular}

baking (PB) was simulated by $185^{\circ} \mathrm{C}$ for $25 \mathrm{~min}$ and threestep paint baking (3-SPB) was simulated with successive 20 min heat treatments at $180^{\circ} \mathrm{C}, 160^{\circ} \mathrm{C}$, and $140^{\circ} \mathrm{C}$. The mechanical properties for these samples were measured at room temperature (RT) in a ZWICK/Z100 at an initial strain rate of $2 \times 10^{-3} \mathrm{~s}^{-1}$. In industrial practice, hot stamped parts are stored before assembling into the space-frame. Therefore, to simulate this, hardness measurements were made at various storage times from 1 to 14 days on the hot stamped "smiley" prototype part using the HB1/10-10 method on a Brinell hardness tester.

2.6. Differential Scanning Calorimetry (DSC). DSC samples were prepared from AW-7921-T4 sheet in the following conditions: as-received T4-condition, W-temper, hot stamped and stored, T6-temper and simulated 1- and 3-step paint baked (SPB). These samples were heated up to $480^{\circ} \mathrm{C}$ in a Netzsch-DSC $204 \mathrm{~F} 1$ with a heating rate of $10 \mathrm{~K} \mathrm{~min}^{-1}$. The endothermic and exothermic peaks in the resulting temperature versus heat flow plots correspond to the dissolution and formation of precipitate, respectively. Differences in the precipitation state of the sheet during the hot stamping processing chain were then concluded from these results. 


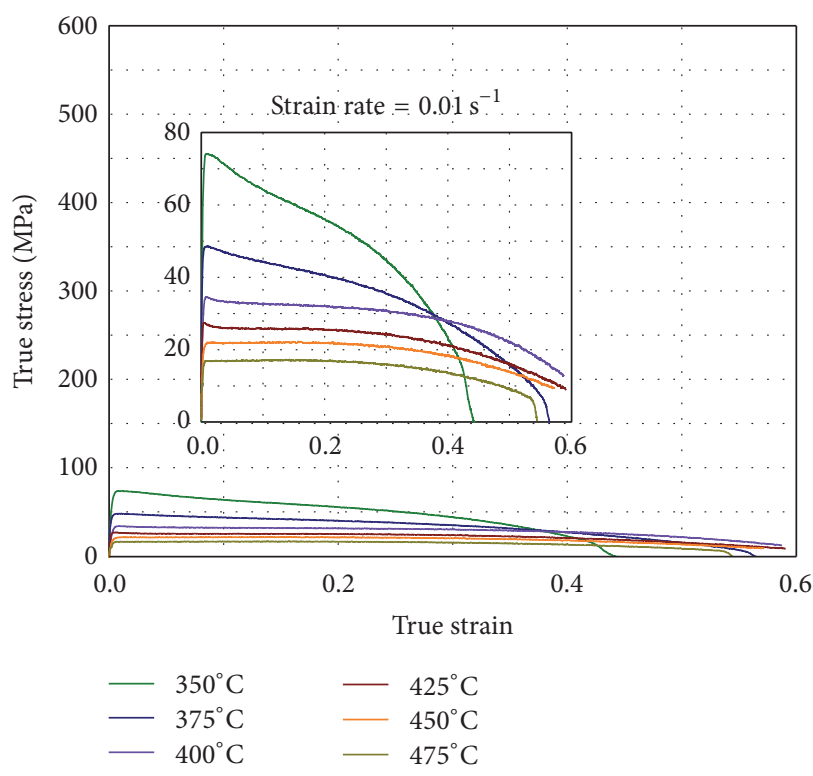

(a)

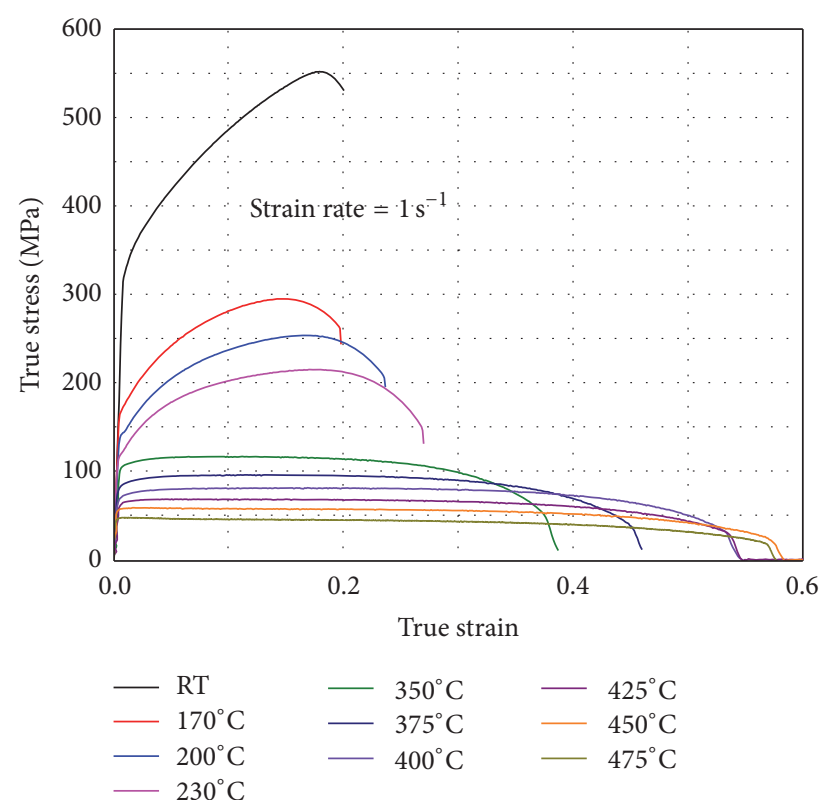

(b)

FIGURE 3: Hot flow curves of the as-received AW-7921-T4 sheet at strain rates of (a) 0.01 and (b) $1 \mathrm{~s}^{-1}$.

\section{Results}

3.1. Flow Curves at Elevated Temperature. Figure 3 shows the flow curves from the dilatometer measurements of the as-received AW-7921-T4 sheet. The measured flow curves at temperatures between 350 and $475^{\circ} \mathrm{C}$ are found to be sensitive to the strain rate, as can be seen by comparing Figures 4(a) and 4(b). At any given test temperature strain rate of $0.01 \mathrm{~s}^{-1}$, the strain-hardening and true stress are considerably lower at the strain rate of $0.01 \mathrm{~s}^{-1}$ than $1 \mathrm{~s}^{-1}$. Additionally, at the $1 \mathrm{~s}^{-1}$ strain rate the true stress and strain-hardening at a strain rate of $1 \mathrm{~s}^{-1}$ decrease faster with increasing test temperature from RT to $350^{\circ} \mathrm{C}$ than from 350 to $475^{\circ} \mathrm{C}$. At temperatures $\geq 350^{\circ} \mathrm{C}$ for this strain rate the true stress after initial yielding reached a steady state. While at $0.01 \mathrm{~s}^{-1}$, the true stress after the peak stress decreases rapidly as indicated by the shape of the flow curves at 350 and $400^{\circ} \mathrm{C}$. This generally occurs due to faster growth and coalescence of voids with decreasing strain rates $[12,13]$.

Yield stress, peak stress, yield stress/peak stress ratio, elongation at fracture, and the strain rate sensitivity $(m)$ were extracted from the flow curves and are plotted in Figure 4. Maximum errors in the measured values were between 1 and $2 \%$. As can be seen in Figure 4(a) the yield stress and peak stress both decrease with increasing temperature and decreasing strain rate.

Formability in sheet materials is determined by measuring the strain-hardening (yield stress/peak stress ratio) and strain rate sensitivity $(m)$ from the flow curves. Only minor changes were observed in the yield/peak stress ratio at the strain rate of $0.01 \mathrm{~s}^{-1}$ with increasing temperature from $350^{\circ} \mathrm{C}$ to $475^{\circ} \mathrm{C}$ and it approaches $\sim 1$ (Figure 4(b)).
A continuous increase in yield stress/peak stress ratio with increasing temperature occurs for the case of $0.1 \mathrm{~s}^{-1}$. At $1 \mathrm{~s}^{-1}$, the yield stress/peak stress ratio first decreases from $350^{\circ} \mathrm{C}$ to $400^{\circ} \mathrm{C}$, but from $400^{\circ} \mathrm{C}$ this value increases.

The effect of strain rate on elongation at fracture is shown in Figure 4(c). Elongation at fracture increases with decreasing strain rates. It was found to be more than 0.82 (the maximum strain measurement limit of the deformation dilatometer) from $400^{\circ} \mathrm{C}$ onwards at both 0.01 and $0.1 \mathrm{~s}^{-1}$. Strain rate sensitivity, $m$, is an important material property in evaluating the formability of a sheet metal. As shown in Figure $4(\mathrm{~d}), m$ has a positive value and is increasing with increasing temperature.

3.2. Precipitation during Cooling of Solution Heat-Treated AA7921-T4 Sheet. Figure 5(a) shows the differential dilatometry (DIL) curves $(d \Delta L / d T$ versus $T)$ for the AA7921 along with a baseline from $99.5 \%$ pure aluminium samples (broken green line AC). Pure aluminium is used for the baseline because there is no precipitation during cooling and therefore yields a straight line. From this line the starting and finishing temperatures for the precipitation reactions in AA7921 may be determined.

The comparison of the DIL curves in Figure 5(a) obtained at different cooling rates clearly shows a deviation in AA7921 compared to the baseline. Similar to the baseline $d \Delta L / d T$ value of the AA7921 alloy decreases on cooling down to $423^{\circ} \mathrm{C}$ (point D) with a cooling rate of $1 \mathrm{~K} \mathrm{~min}^{-1}$. A deviation with respect to the baseline then occurs in the form of faster contraction (increase in $d \Delta L / d T$ ) with a peak $(B)$ at $370^{\circ} \mathrm{C}$. On further cooling below $370^{\circ} \mathrm{C}$, the $d \Delta L / d T$ value starts to decrease and amount of decrement slows down. The start and 


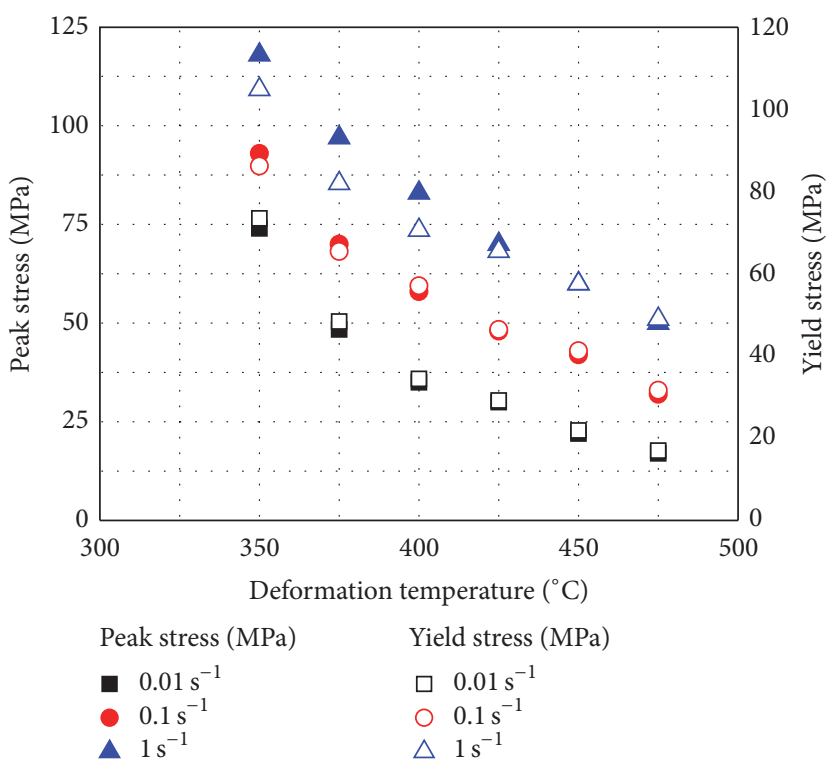

(a)

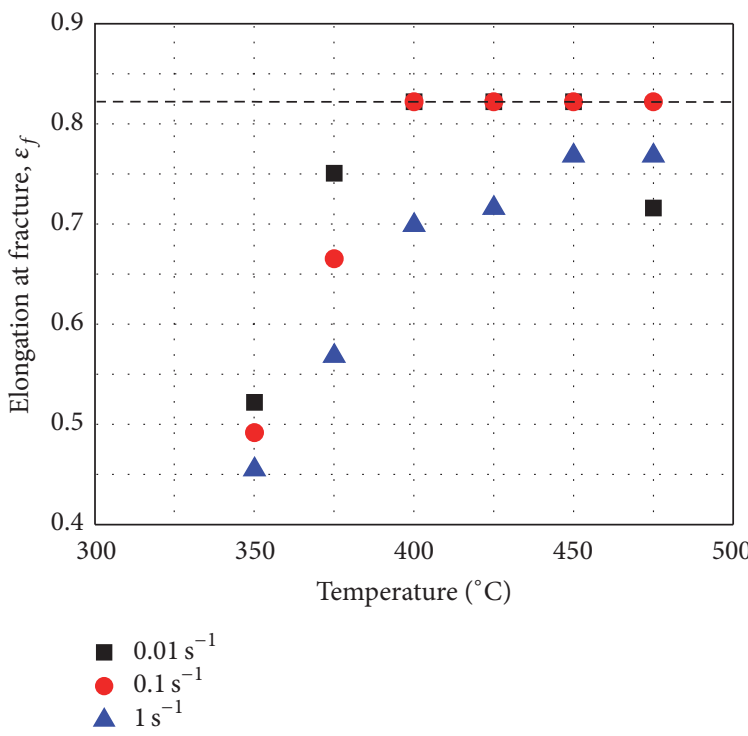

(c)

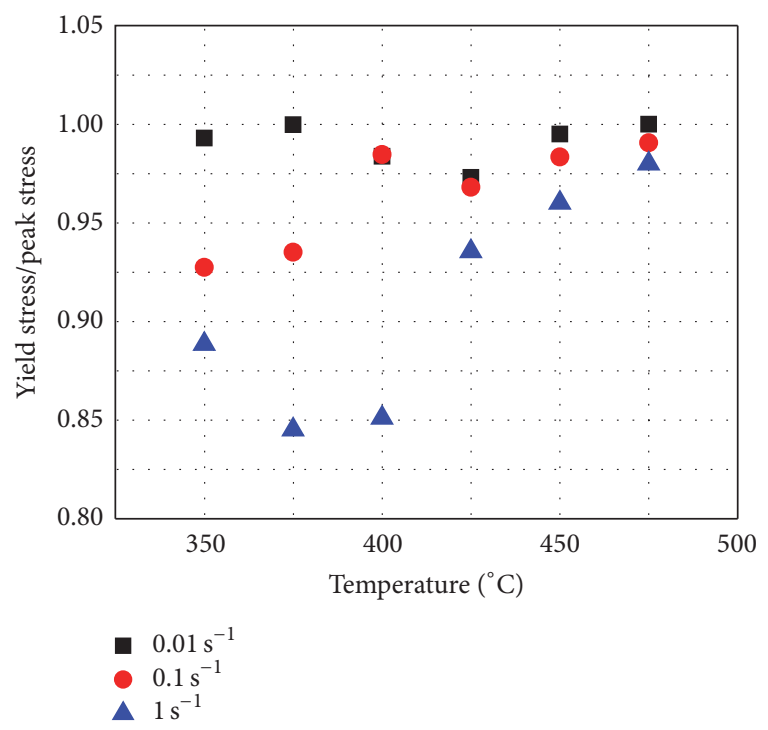

(b)

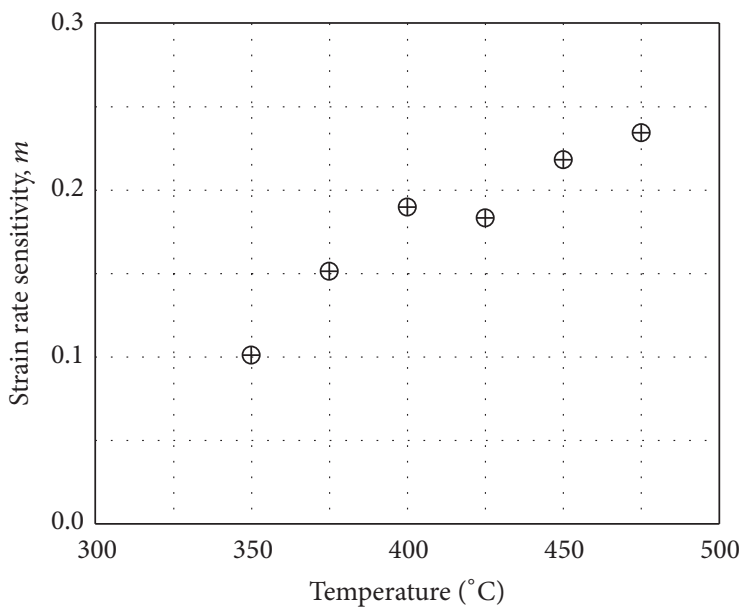

$\oplus$ Measured at peak stress

(d)

Figure 4: (a) Peak and yield stress, (b) yield stress/peak stress ratio, (c) elongation at fracture, and (d) strain rate sensitivity of AW-7921-T4 at temperatures between 350 and $475^{\circ} \mathrm{C}$ and at strain rates between 0.01 and $1 \mathrm{~s}^{-1}$. The dashed line in (c) indicates the measurement limit for the deformation dilatometer.

finish temperatures for this peak are $423^{\circ} \mathrm{C}$ and $200^{\circ} \mathrm{C}$. As indicated by arrows the temperature and height of the peak $B$ decrease with increasing cooling rate.

Precipitation during cooling is generally described by continuous cooling transformation (CCT) diagram. A simulated CCT diagram for $0.5 \%$ transformation fraction using JMATPRO software is shown in Figure 5(b). In this CCT diagram it is shown that the precipitation of stable $\eta$ phase (MGZN2) and T-phase (T-ALCUMGZN) has finished around $200^{\circ} \mathrm{C}$. Therefore, at cooling rates $\geq 5 \mathrm{~K} \mathrm{~s}^{-1}$ the precipitation of these two phases will be suppressed.
3.3. Hardness. Figure 6(a) shows the hardness of the specimens taken from the AA7921 sheet in different heat-treated or hot stamped conditions. A solution heat treatment (SHT) at $480^{\circ} \mathrm{C}$ for $30 \mathrm{~min}$ was applied to the as-received AA7921 sheet, followed by water quenching (WQ) to room temperature. Thereafter, the hardness was measured with respect to storage (natural ageing) time. The hardness of the SHT + WQ sample increased from 80 to $150 \mathrm{HB}$ due to storage for $336 \mathrm{~h}$ (two weeks).

In the "smiley" prototype part hot stamped at two different speeds ( 10 and $20 \mathrm{~mm} \mathrm{~s}^{-1}$ ), stamping speed produces only a minor difference in the hardness measured - between 

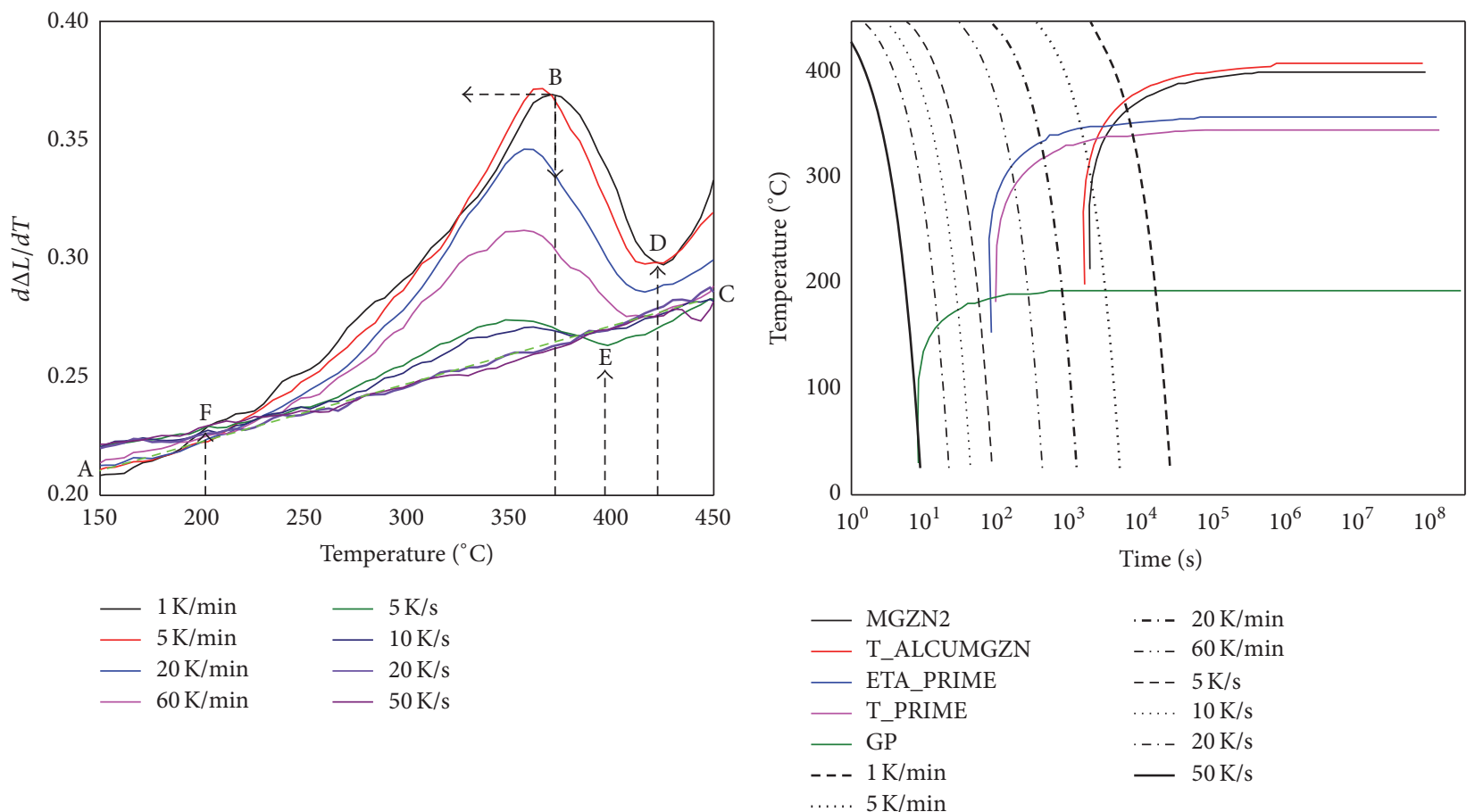

(a)

(b)

FIGURE 5: (a) DIL curves for AA7921 measured at various cooling rates between $1 \mathrm{~K} \mathrm{~min}^{-1}$ and $50 \mathrm{~K} \mathrm{~s}^{-1}$. (b) Simulated CCT diagram of AA7921 from JMATPRO software.

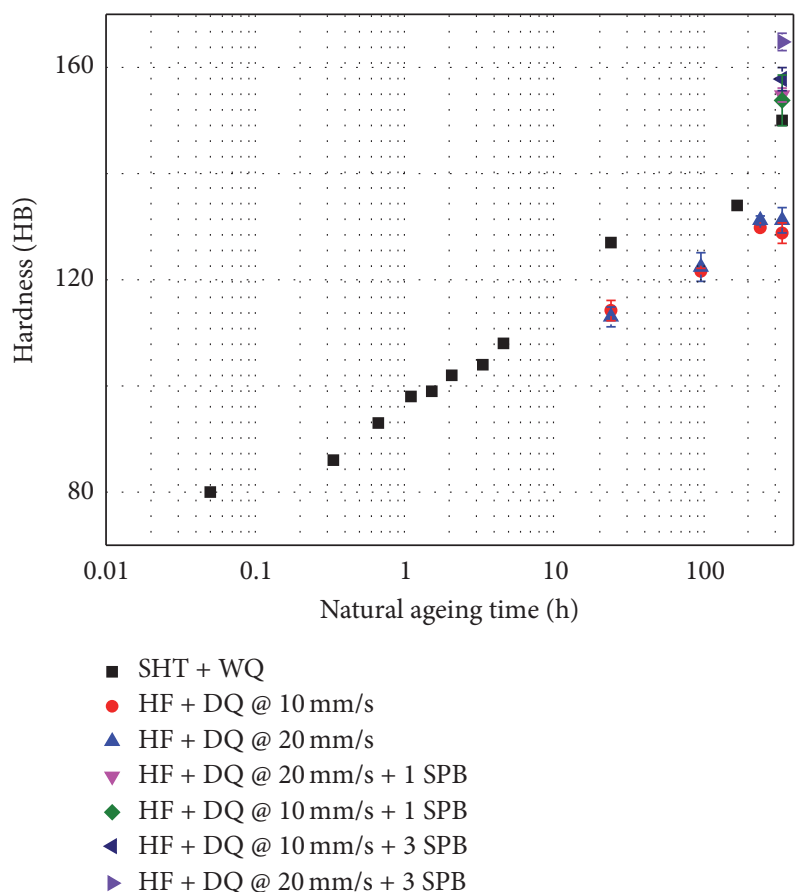

(a)

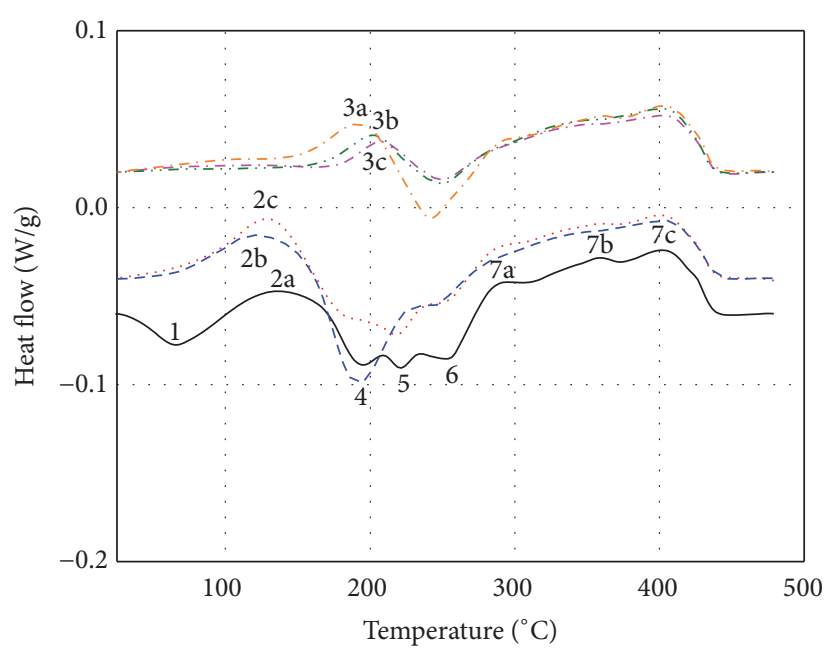

$\begin{array}{ll} & \text { W-temper } \\ \ldots . . . & \text { T4-temper } \\ --- & \text { Hot stamping + 2-week storage } \\ -.- & \text { 1-SPB } \\ -\cdots- & \text { 3-SPB } \\ -.- & \text { T6-temper }\end{array}$

(b)

FIGURE 6: (a) Hardness of the side-wall "smiley" prototype samples following 2 weeks of storage, as well as after subsequent 1-step and 3-step paint baking. HF + DQ refers to hot forming and subsequent die quenching. (b) DSC curves of AA7921 in W-temper, T4-temper, and hot stamping followed by 2 weeks of natural ageing and after two different subsequent paint baking procedures (1-step and 3-step paint baking (1- and 3-SPB)). These DSC curves compared with the DSC curve of AA7921 in the T6 condition. 
1-3 HB - following the $336 \mathrm{~h}$ ( 2 weeks) storage. It is interesting to note that after two weeks of storage the hardness of the hot stamped samples is significantly lower-by $19 \mathrm{HB}$-than the SHT + WQ sample. The speed of hot stamping has no significant influence on hardness of the samples after hot stamping and two weeks storage, as well as after subsequent one-step paint baking. However, when a three-SPB is applied the three-SPB instead of one-SPB, the hardness of the sample hot stamped at $20 \mathrm{mms}^{-1}$ increases to 165 which is $7 \mathrm{HB}$ higher than the sample hot stamped at $10 \mathrm{~mm} \mathrm{~s}^{-1}$. It is important to note here that the single step paint baking heat treatment is different to the 3-step process and that the latter is not a continuation of the former.

3.4. Characterization of Tempers by DSC. The DSC results were analysed based on a dilatometry technique investigation of the precipitation kinetics during nonisothermal heating of various heat-treated $\mathrm{Al}-\mathrm{Zn}-\mathrm{Mg}$ alloy samples [14]. In that investigation it was found that the interval temperatures $20-120^{\circ} \mathrm{C}, 120-250^{\circ} \mathrm{C}$, and $150-300^{\circ} \mathrm{C}$ correspond, respectively, to the formation of GP Zones, $\eta^{\prime}$ and $\eta$ phases, and the interval temperatures $50-150^{\circ} \mathrm{C}, 200-250^{\circ} \mathrm{C}$, and $300-$ $350^{\circ} \mathrm{C}$ correspond, respectively, to their dissolution. However, formation and dissolution interval temperatures depend on alloy composition, heating rate, and the initial temper of the material.

Figure 6(b) shows DSC curves of the AW-7921 sheet in various heat-treated or thermomechanically treated conditions. A total of 7 peaks appear in the DSC curves. On heating the SHT + WQ sample, that is, AA-7921-W-temper, an exothermic peak (Peak 1 ) appears at approximately $66^{\circ} \mathrm{C}$ relating to the formation of GP Zones. This means the sample was in a supersaturated solid solution condition prior to the test. At $140^{\circ} \mathrm{C}$ these GP Zones dissolve as indicated by peak $2 \mathrm{a}$, on further heating phases $\eta^{\prime}$ and $\eta$ and T precipitate (peaks 4, 5, and 6). And, finally, these three phases dissolve as shown by the broad overlapping endothermic peaks $7(\mathrm{a}-\mathrm{c})$ between 290 and $400^{\circ} \mathrm{C}$.

The formation peak for GP Zones is not present for the other samples. However, their dissolution is seen in the curve of the hot stamped + two weeks of natural ageing sample and the T4-temper (SHT + WQ + two weeks of natural ageing) sample, as indicated by the endothermic peaks (2b) and (2c) around $121^{\circ} \mathrm{C}$ and $130^{\circ} \mathrm{C}$, respectively. It shows that GP Zones were already present in the sheet before the test and these would have formed during storage (natural ageing). There are endothermic peaks present at $193^{\circ} \mathrm{C}(3 \mathrm{a}), 207^{\circ} \mathrm{C}(3 \mathrm{~b})$, and $203^{\circ} \mathrm{C}(3 \mathrm{c})$ for the T6-temper sample and the hot stamped 1and 3-SPB samples (Figure 6(b)). This shows the endothermic peak 3 (dissolution of $\eta^{\prime}$ ) shifts towards lower temperatures in the order of 1-SPB, 3-SPB, and then T6 heat treatment. These results from the DSC investigation provide information about the precipitate microstructure present in the heat-treated, hot stamped, and paint baked conditions as listed in Table 3.

3.5. Hot Stamping Process Chain. The process steps in the hot stamping process chain have been described in the beginning (Figure 1). It can be expected that process steps such as preheating, forming, and storage and finally the paint baking
TABLE 3: Condition and precipitate microstructure for AW-7921 sheet for the various tempers, as discerned from the DSC measurements.

\begin{tabular}{lc}
\hline Temper & Precipitate microstructure \\
\hline SHT + WQ: W-temper & Zn and Mg solutes \\
SHT + WQ + 2-week storage: T4-temper & GP Zone \\
HF + DQ @ 10 mm/s + two-week storage & GP Zone \\
1-SPB & $\eta^{\prime}$ precipitate \\
3-SPB & $\eta^{\prime}$ precipitate \\
T6 & $\eta^{\prime}$ precipitate \\
\hline
\end{tabular}

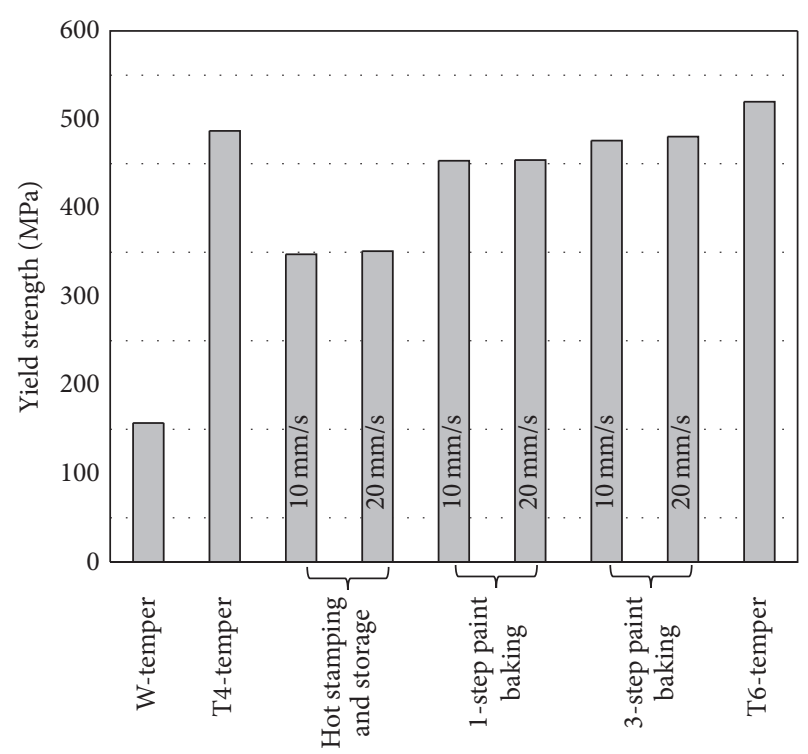

FIGURE 7: Effect of process steps on the yield strength of AW-7921 sheet in the warm forming process chain. The speeds shown are the rates for hot forming. All measurements made at RT except for the preheat treatment measurements. These were measured at $230^{\circ} \mathrm{C}$.

treatment, would alter the mechanical properties of the sheet. Figure 7 shows these changes by comparing the effects of the process steps on the yield strength of the sheet. As expected, the SHT + WQ considerably decrease the yield strength of the as-received AA7921 sheet (Figure 7). After hot stamping this sheet (for both the $10 \mathrm{~mm} \mathrm{~s}^{-1}$ and $20 \mathrm{~mm} \mathrm{~s}^{-1}$ ) and storing it for two weeks the yield strength increases to approximately $350 \mathrm{MPa}$. It is clear from Figure 7 that the development of yield strength during paint baking depends on the paint baking heat treatment procedure. Following a 1-SPB treatment the yield strength of hot stamped sheet $\left(10 \mathrm{~mm} \mathrm{~s}^{-1}\right.$ and $20 \mathrm{~mm} \mathrm{~s}^{-1}$ ) with two weeks storage increases up to $450 \mathrm{MPa}$, while the yield strength increases up to $480 \mathrm{MPa}$ with the 3-SPB. However, the final yield strength was still lower than the theoretical maximum of the T6-condition (520 MPa).

\section{Discussions}

Fine dispersed metastable precipitates are generally responsible for strength in age-hardenable aluminium alloys, for 
example, GP Zones in T4 and $\eta^{\prime}$ precipitates in T6 tempers. These metastable precipitates form in a sequence. Löffler et al. [15] reviewed the sequence of precipitation in AW-7xxx alloys and have observed following precipitation sequence, that is, $\alpha$-supersaturated solid solution-Al $\rightarrow$ GP Zones $\rightarrow \eta^{\prime} \rightarrow \eta^{-}$ $\mathrm{MgZn}_{2}$ or T-phase.

$\mathrm{Zn}$ and $\mathrm{Mg}$ are the main alloying elements for AA7921 alloy having atomic diameters 0.266 and $0.32 \mathrm{~nm}$ which are, respectively, $12 \%$ larger and $7 \%$ smaller than the atomic diameter of Al. These solute atoms form a substitution solid solution when dissolved into the Al-matrix. The structure of the solid solution remains the same as that of the Al-matrix (i.e., face-centred cubic) with a lattice parameter for the Almatrix of $0.405 \mathrm{~nm}$ and unit cell volume of $0.0664 \mathrm{~nm}^{3}$. For the $\eta^{\prime}$ (ETA_PRIME) and $\eta$ (MGZN2) phases the unit cell volumes are $0.202 \mathrm{~nm}^{3}$ (lattice parameters of $\eta^{\prime}$ phase: $a=$ $0.521 \mathrm{~nm}, c=0.86 \mathrm{~nm}$ ) and $0.299 \mathrm{~nm}^{3}$ (lattice parameters of $\eta$ phase: $a=0.496 \mathrm{~nm}, c=1.403 \mathrm{~nm}$ ) [16]. Therefore, precipitation of these phases during continuous cooling will bring additional changes in alloy volume in addition to the changes caused by temperature. This leads to the nonlinear change of $d \Delta L / d T$ seen in Figure 3(b) [17].

Solution heat-treated state after quenching in water consists of solute atoms and quenched-in-vacancies. This state is called W-temper. Since the concentrations of solute atoms and vacancies are more than the equilibrium value, W-temper readily decomposes during continuous heating or during natural ageing. During decomposition, supersaturated solute atoms and quenched-in-vacancies cluster together and precipitates as GP Zones as reflected in the DSC heat flow signal by a broad exothermic peak at temperature of $66^{\circ} \mathrm{C}$ during continuous heating. Meanwhile, during natural ageing, decomposition is reflected by the broad endothermic peak (GP Zone dissolution) around $130^{\circ} \mathrm{C}$ (Figure 6(b)). This state is called T4-temper.

It is clear that GP Zones precipitate during natural ageing and cause increase in hardness from $\mathrm{W}$-temper to T4-temper (Figure 6(a)). There is a small difference in the hardness of T4-temper and hot formed and die quenched parts after two weeks. This is related to the introduction of dislocations and quenched-in-vacancies into the parts after hot forming and subsequent die quenching ( $\mathrm{HF}+\mathrm{DQ})$. Since dislocations act as vacancy sinks a slowing down of precipitation kinetics occurs due to progressive annihilation of quenched-in vacancies on dislocations [18].

Dynamic mechanisms such as strain-hardening, dynamic recovery, dynamic precipitation and/or coarsening of precipitates generally occur during hot deformation of precipitation hardening aluminium alloys. Additionally, diffusion controlled growth of microvoids/cracks is also reflected in the flow behaviour at slower strain rates. The DSC investigation above confirmed that the AW-7921 sheet in the T4 temper contains GP Zones (Figure 6(b)). This phase partially dissolves during deformation at elevated temperature, as shown by $[19,20]$. The amount of dissolution of precipitates increases with increasing temperature. This dissolution explains the decrease in yield stress of AW-7921-T4 sheet with increasing temperature up to $475^{\circ} \mathrm{C}$.
The decrease in the yield stress and peak stress of AW7921-T4 with increasing temperature may be, respectively, attributed to increasing dissolution of hardening GP Zone precipitates and dynamic recovery. Dynamic recovery occurs during deformation at elevated temperatures. Generally, it leads to steady state deformation due to annihilation of dislocations by cross-slip and climb supported by the applied stress and increased diffusion $[13,21]$. The dynamic recovery effect increases with increasing temperature due to diminished strain-hardening through the annihilation of the accumulated dislocations. This is observed in the tensile behaviour (Figure 4(b)). As temperature is increased the ratio of the yield stress to the peak stress approaches 1 and indicates reducing strain-hardening.

The strain rate effects on yield and peak stress in the current work can be understood in terms of the time until fracture at the test temperature. Decreasing strain rate increases deformation periods and this is believed to lead to more dynamic recovery and dissolution of GP Zone precipitates during the test. Higher strain rates increase the strain-hardening capacity and results in an increase in peak stress as shown in Figures 4(a) and 4(b), respectively. It is believed that a slower strain rate allows much more time for dynamic recovery than higher strain rate due to longer exposure at the test temperature. This leads to the lower yield strength at $0.01 \mathrm{~s}^{-1}$ compared to 0.1 and $1 \mathrm{~s}^{-1}$.

Formability of AW-7921-T4 sheet can be related to the elongation at fracture and strain rate sensitivity, $m$. The positive strain rate sensitivity increases deformation resistance and the local deformation slows down. With the increase of strain rate sensitivity, the transfer and diffusion capability of necking increase [13]. Therefore, increasing strain rate sensitivity along with dynamic recovery seems to be responsible for the increase in elongation at fracture with increasing temperature.

The decrease in yield strength $(\sim 28 \%)$ from the initial T4temper condition to the hot stamped and stored condition is negligible for both forming speeds (Figure 7). After a subsequent 1-SPB heat treatment the yield strength of hot stamped and stored parts increases by $\sim 29 \%$ due to the formation of hardening $\eta^{\prime}$ precipitates. However, when using the 3-SPB instead of the 1-SPB, the yield strength increases by $\sim 37 \%$. The hot stamped and stored part exhibited the highest yield strength after the 3-step paint baking treatment $(\sim 480 \mathrm{MPa})$, but this is still only $92 \%$ of the T6-temper yield strength $(\sim 520 \mathrm{MPa})$. Therefore, there is a need for further optimisation of the paint bake treatment to achieve the peak-aged strength in the completed part. Alternatively, a heat treatment to stabilize the GP Zones may be given after forming allowing them to act as nucleation sites for $\eta^{\prime}$ precipitates.

\section{Conclusions}

This work has investigated the hot stamping behaviour of AW-7921 sheet on the formability and final mechanical properties as the sheet passes through the process chain. It has shown the importance of considering the whole process chain and the effects of the thermomechanical processing 
contained therein. This consideration is important to ensure (1) the best conditions for forming the part and (2) the highest possible strength is achieved in the final product. The main findings are as follows:

(1) The cooling rate during hot forming and die quenching should be at least between 5 and $10 \mathrm{~K} \mathrm{~s}^{-1}$.

(2) Tensile test results show that the AW-7921 alloy is sensitive to temperature and strain rate. The YS and UTS decrease with increasing temperature and decreasing strain rate. Strain rate sensitivity, $m$, and elongation at fracture increase with increasing temperature and decreasing strain rate. This is due to dynamic recovery and dissolution of hardening precipitates, for instance, GP Zones.

(3) The yield strength of AW-7921 samples increases in the order of 1-SPB, 3-SPB, and T6-temper. This is related to the increasing stability of the $\eta^{\prime}$ precipitates present in the samples.

(4) Forming speeds of 10 and $20 \mathrm{~mm} \mathrm{~s}^{-1}$ produced almost identical yield strengths in the hot stamped parts.

(5) The final hot stamped component following a 3-step paint bake process exhibited yield strength of $92 \%$ achievable with a T6-temper, while for 1 step paint baking the yield strength was $84 \%$.

\section{Disclosure}

The current address of M. Kumar is as follows: Ebner Industrieofenbau GmbH, Ebner-Platz 1, 4060 Leonding, Austria.

\section{Competing Interests}

The authors declare that they have no competing interests.

\section{Acknowledgments}

The authors would like to thank the European Regional Development Fund (EFRE) and the State of Upper Austria for sponsoring the project ForMAT in the framework of the EUProgramme Regio 13. The authors' grateful thanks go to their technicians, in particular Anton Hinterberger and Christian Haslinger, for their support throughout the research work.

\section{References}

[1] N. R. Harrison and S. G. Luckey, "Hot stamping of a Bpillar outer from high strength aluminum sheet AA7075," SAE International Journal of Materials and Manufacturing, vol. 7, no. 3, pp. 567-573, 2014.

[2] J. Dörr, Semi-Hot and Hot Forming of Conventional and High Strength Aluminum Alloys, Forming in Car Body Engineering, ACI, Bad Nauheim, Germany, 2011.

[3] R. Kelsch, "Aluminium in the car body-new forming concepts for performance improvement and spread of scope," in Strategies in Car Body Engineering, ACI, Bad Nauheim, Germany, 2013.
[4] M. Kumar and N. G. Ross, "Influence of temper on the performance of a high-strength $\mathrm{Al}-\mathrm{Zn}-\mathrm{Mg}$ alloy sheet in the warm forming processing chain," Journal of Materials Processing Technology, vol. 231, pp. 189-198, 2016.

[5] E. Ceretti, C. Contri, and C. Giardini, "Tube-hydroforming experiments on an Al 7003 extruded tube," Journal of Materials Processing Technology, vol. 177, no. 1-3, pp. 672-675, 2006.

[6] M. Kumar, N. Sotirov, and C. M. Chimani, "Investigations on warm forming of AW-7020-T6 alloy sheet," Journal of Materials Processing Technology, vol. 214, no. 8, pp. 1769-1776, 2014.

[7] H. Wang, Y.-B. Luo, P. Friedman, M.-H. Chen, and L. Gao, "Warm forming behavior of high strength aluminum alloy AA7075," Transactions of Nonferrous Metals Society of China, vol. 22, no. 1, pp. 1-7, 2012.

[8] M.-Y. Lee, S.-M. Sohn, C.-Y. Kang, D.-W. Suh, and S.-Y. Lee, "Effects of pre-treatment conditions on warm hydroformability of 7075 aluminum tubes," Journal of Materials Processing Technology, vol. 155-156, no. 1-3, pp. 1337-1343, 2004.

[9] L. Wang, M. Strangwood, D. Balint, J. Lin, and T. A. Dean, "Formability and failure mechanisms of AA2024 under hot forming conditions," Materials Science and Engineering: A, vol. 528, no. 6, pp. 2648-2656, 2011.

[10] M. S. Mohamed, A. D. Foster, J. Lin, D. S. Balint, and T. A. Dean, "Investigation of deformation and failure features in hot stamping of AA6082: experimentation and modelling," International Journal of Machine Tools \& Manufacture, vol. 53, no. 1, pp. 27-38, 2012.

[11] P. F. Bariani, S. Bruschi, A. Ghiotti, and F. Michieletto, "Hot stamping of AA5083 aluminium alloy sheets," CIRP AnnalsManufacturing Technology, vol. 62, no. 1, pp. 251-254, 2013.

[12] M. Kumar, Precipitation kinetics in thermo-mechanical forming of aluminium alloys [Ph.D. thesis], TU Wien, Vienna, Austria, 2011.

[13] M. Zhou, Y. Lin, J. Deng, and Y. Jiang, "Hot tensile deformation behaviors and constitutive model of an $\mathrm{Al}-\mathrm{Zn}-\mathrm{Mg}-\mathrm{Cu}$ alloy," Materials \& Design, vol. 59, pp. 141-150, 2014.

[14] L. Hadjadj, R. Amira, D. Hamana, and A. Mosbah, "Characterization of precipitation and phase transformations in $\mathrm{Al}-\mathrm{Zn}$ $\mathrm{Mg}$ alloy by the differential dilatometry," Journal of Alloys and Compounds, vol. 462, no. 1-2, pp. 279-283, 2008.

[15] H. Löffler, I. Kovacs, and J. Lendvai, "Decomposition processes in Al-Zn-Mg alloys," Journal of Materials Science, vol. 18, no. 8, pp. 2215-2240, 1983.

[16] L. Hadjadj, R. Amira, D. Hamana, and A. Mosbah, "Characterization of precipitation and phase transformations in $\mathrm{Al}-\mathrm{Zn}$ $\mathrm{Mg}$ alloy by the differential dilatometry," Journal of Alloys and Compounds, vol. 462, no. 1-2, pp. 279-283, 2008.

[17] M. Kumar, N. Ross, and I. Baumgartner, "Development of a continuous cooling transformation diagram for an $\mathrm{Al}-\mathrm{Zn}-\mathrm{Mg}$ alloy using dilatometry," Materials Science Forum, vol. 828-829, pp. 188-193, 2015.

[18] S. Ceresara and P. Fiorini, "Resistometric investigation of the ageing process after quenching and cold-work in Al-Zn-Mg alloys," Materials Science and Engineering, vol. 10, pp. 205-210, 1972.

[19] T. Marlaud, A. Deschamps, F. Bley, W. Lefebvre, and B. Baroux, "Evolution of precipitate microstructures during the retrogression and re-ageing heat treatment of an Al-Zn-Mg-Cu alloy," Acta Materialia, vol. 58, no. 14, pp. 4814-4826, 2010. 
[20] M. Kumar, C. Poletti, and H. P. Degischer, "Precipitation kinetics in warm forming of AW-7020 alloy," Materials Science and Engineering: A, vol. 561, pp. 362-370, 2013.

[21] M. Kumar, C. Poletti, and H. P. Degischer, "Precipitation kinetics in warm forming of AW-7020 alloy," Materials Science and Engineering A, vol. 561, pp. 362-370, 2013. 

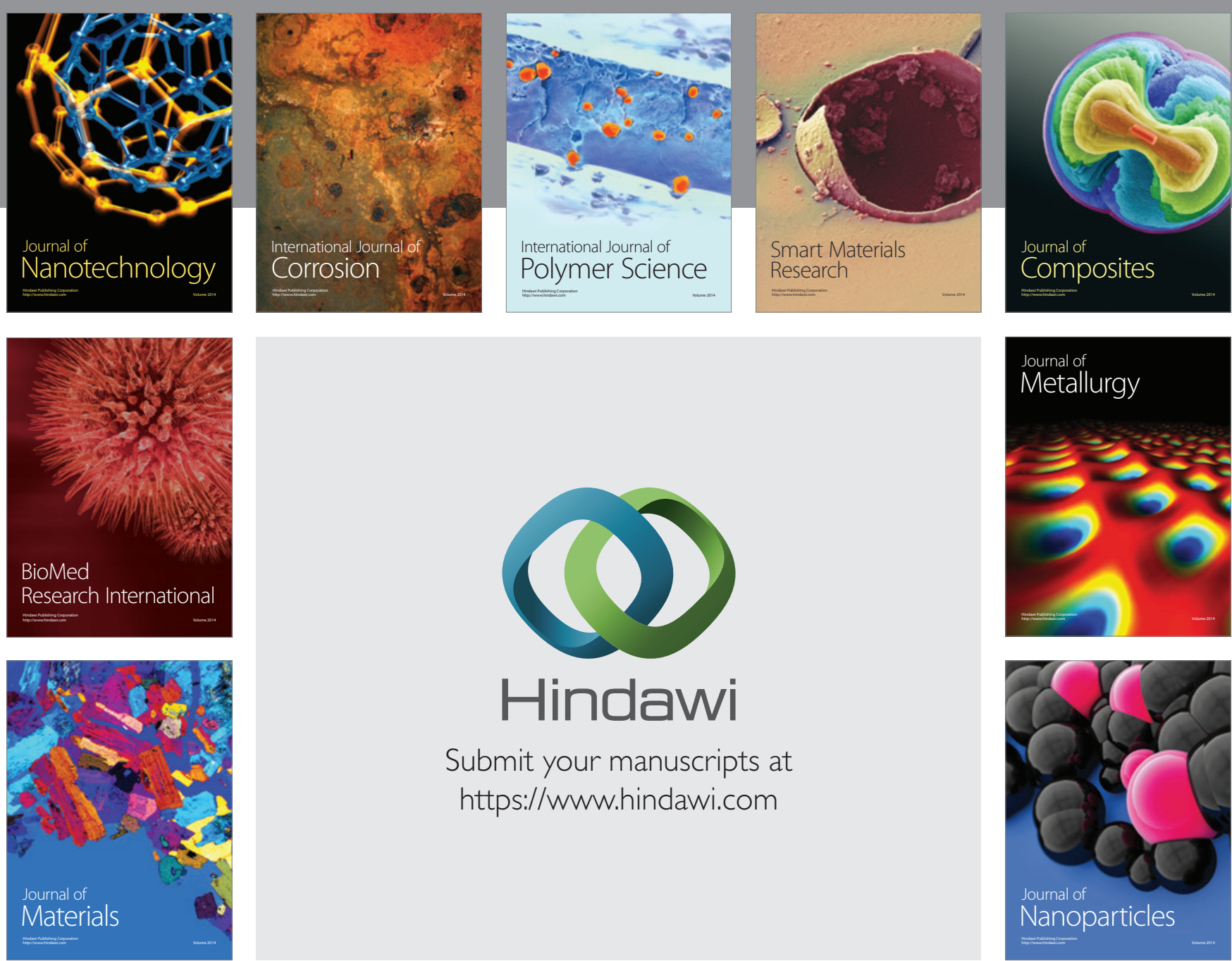

\section{Hindawi}

Submit your manuscripts at

https://www.hindawi.com

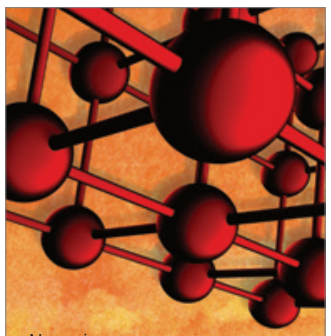

Materials Science and Engineering
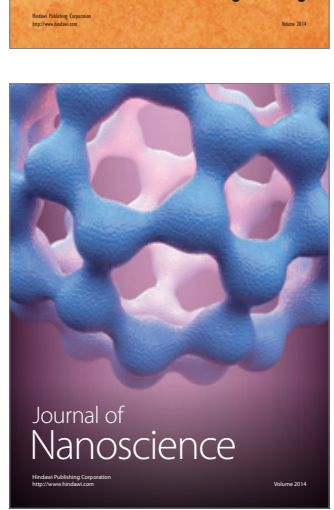
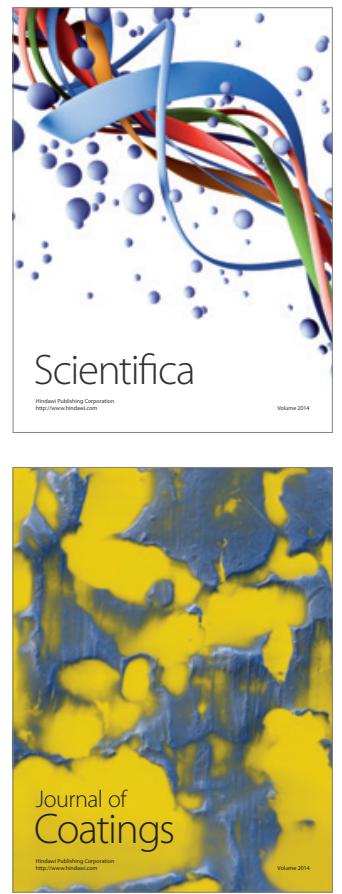
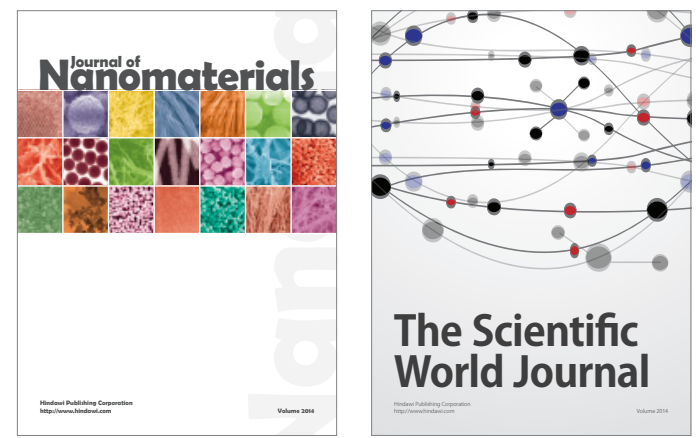

The Scientific World Journal
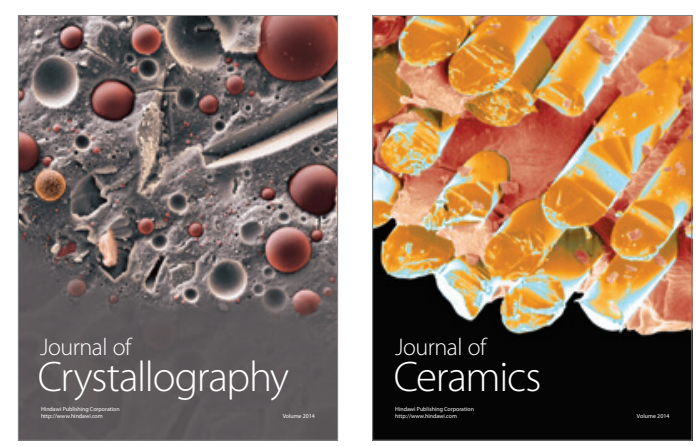
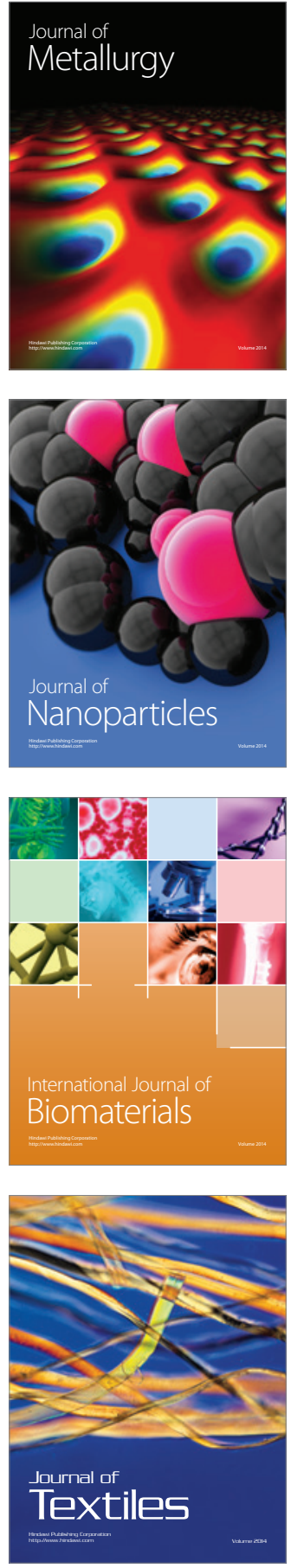